\title{
Interpersonal and Social Empathy toward Openness to Diversity of Humanities and Social Sciences Students
}

\author{
Rhea Amor P. Lara ${ }^{1}$, Christon Cain M. Maglente ${ }^{2}$, Karen R. Bolambot ${ }^{3}$, Ronel G. Dagohoy ${ }^{4}$ \\ ${ }^{I}$ Student, Bachelor of Science in Social Work, Davao del Norte State College \\ ${ }^{2}$ Student, Bachelor of Science in Information Technology, Davao del Norte State College \\ ${ }^{3}$ Student, Sto. Tomas College of Agriculture, Sciences and Technology \\ ${ }^{4}$ Program Chairperson, Bachelor of Public Administration, Davao del Norte State College \\ DOI: https://dx.doi.org/10.47772/IJRISS.2021.5405
}

\begin{abstract}
Openness to diversity is vital in improving internal group positive relationship. This study examined the influence of interpersonal and social empathy toward openness to diversity of Humanities and Social Sciences (HUMSS) students. Furthermore, it delves what factor of interpersonal and social empathy significantly influences the openness to diversity of HUMSS students. Primary data were collected directly from the respondents through two adapted scales. The descriptivecorrelation method of research was used to attain the study's objectives. The respondents of this study were the 123 grade 12 HUMSS students of Sto. Tomas National High School from school year 2019 - 2020. The findings of the study revealed that the level of interpersonal and social empathy and openness to diversity of senior high school students are both high. It was also revealed that there is a positive, high and significant relationship between interpersonal and social empathy and openness to diversity. Moreover, it was found out that the macro-perspective taking and self-other awareness are the domains that significantly influence openness to diversity. This means that if the students show consideration and sensible with other's way of living there is a great possibility that they are open with diversity.
\end{abstract}

Keywords: Interpersonal and Social Empathy, Openness to Diversity, Senior High School, Philippines

\section{INTRODUCTION}

\subsection{Background of the Study}

$\mathrm{O}$ penness to diversity is essential as it helps to improve internal group relationships and build a positive relationship with the members of an internal group [1]. However, ethnocentrism is spreading universally and is considered as an undesirable attitude in which ethnocentric people possess a biased opinion in favor of their group, and they believed that their culture is superior to the others that cause racism, prejudice, and inequality treatment to the out group members [2]. Also, surveys found that diversity generates misunderstanding, quarrels, and favouritism in society, which are also a product of ethnocentricity [3]. Furthermore, if the education system is prone to diversity, there is a possibility that the condemned group will discern barriers in education [4].

Openness diversity is essential in promoting a team effort and the spillover of new ideas and different perspective that increases recombination of abilities and knowledge [5]. Besides, because of the increasing of the globalization people are required to communicate with others with different beliefs and culture. Being open to diversity will help people to be more creative and, eventually, promotes the productivity of society. Therefore, being open to diversity developed a fruitful and competitive advantage in a community [6].

There are numerous studies on openness to diversity that link with different factors. For instance, openness to diversity was link with interpersonal and social empathy [7]. Interpersonal and social empathy serves as a vital attitude and behavior of being open of a person to other's cultures. Besides, individual and group empathy mediates the effects of diversity in society as well as in the performance of the individual [3]. Despite the current literature about diversity, the researchers have not come across a study that investigates the link on interpersonal and social empathy toward openness to diversity of Humanities and Social Sciences students, particularly in local settings. Hence, the researchers are persuaded to conduct this study to fill the gap in the literature covering these subjects, especially in the local context.

The study will assess the link between interpersonal and social empathy and openness to the diversity of the senior high school students, particularly in the Humanities and Social Sciences (HUMSS) strand. The results will give vital information to the teachers if the interpersonal and social empathy affects openness to the diversity of the students.

\subsection{Theoretical Framework}

This study is anchored in three theories. The first theory is the Social Identity Theory [8]. This theory stated that a person's perception of who they are is based on the group where they belong. It is believed that the world is divided through social categorization into them that refers to the out-group and "us," which refers to the in-group. This categorization causes stereotyping and prejudice attitude because of them and us mentality. This theory is related to our variable, which is the openness to diversity that refers to open-mindedness and the acceptance of a person in another's culture. 
Another theory is theTheory of Empathy of Hoffman [9]. Hoffman's theory centralized empathic distress as an evolutionary trait that is connected with helping and precedes helping and feel better after helping. Furthermore, his theory also emphasizes that a person's virtuous composition, which includes behaviors, perceptions, the belief of right from wrong, and the self-blame and guilt, is a network of emphatic distress. Hoffman explains that socialization precedes internalization. This is connected with our dependent variable because internal and social empathy improves contextual understanding.

Finally, the Theory of Social Development, this asserts that interacting with other people lead up to development [10]. Awareness, learning, and being conscious is a result of socialization and social behavior. Vygotsky believes that interaction will help people to develop with another culture, and here is the aftermath; if the people interact with others, it will build his/her thinking skills. It is connected with our study because interpersonal and social empathy will positively have developed being open-minded to diversity.

\subsection{Conceptual Framework}

Presented in figure 1 is the conceptual framework of the variables of the study. The first box contains the independent variable of the study, which refers to the interpersonal and social empathy, while the second box contains the dependent variable of the study, which refers to the openness to diversity.

The dependent variable of this study is the interpersonal and social empathy that will measure the dependent variable, which is the openness to diversity; the independent variable has six components.

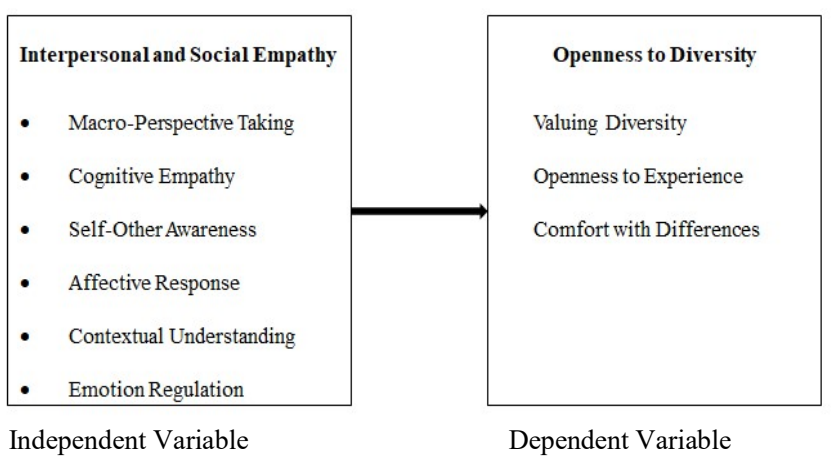

Figure 1: Conceptual Framework Showing the Variables of the Study

The first component is macro-perspective taking. It is also known as "put oneself in someone's shoes" is a process in which an observer successfully understands other's way of life that may result from experiencing the experiences of others personally. Thus, for people to fully comprehend the life experiences of another person that is different from themselves, they should step into the lives of those groups of people that differ from them [11].
Cognitive empathy: It is defined as metalizing about the affective life of others. It is to identify another's mental state or way of living [12]. Then, self-other awareness. It is defined as the capacity of a person to differentiate his experiences to the experiences of another person. This process will lead to an empathic response to a cognitive arena [11].

Affective response: Neurological pathways of the brain are capable of psychological simulating of other's experiences and this process in which affective response originates. This is often about a "mirroring," which refers to connecting with another person [11].

Contextual Understanding: Studies have found out that understanding in a social context and the quality to established conditions of other people in a particular group is an essential constituent of empathy across cultures [13].

Emotion Regulation: The ability to feel another's feelings without becoming overwhelmed is mediated by emotion regulation. It is said that without this factor a person could be overwhelmed, feel sympathy or be but not feel empathy [11].

The dependent variable of this study is the openness to diversity that could lessen the group's antipathy and, at the same time, have a positive effect on a group's reliance. It also supports the social interactions within the groups [14].

Valuing diversity: It is how people communicate and interact with another group that has different orientations and beliefs from them. The difference of the other must be handle converge on valuing the diversity, it enhances the learning process, learning the different cultures from diverse groups that set apart our experience that could change your life situations [15].

Openness to experience: It is used to measure the genuine of being open to a different culture and practices (fiesta, festivals, and new places) that serve as new knowledge for them. While, comfort with differences measures how you are open to diversity to level the sympathy and acquiring the different experiences, because of the age gap obtaining and taking differences together with the other people whose gender is different from us, as our comfort zone from diversity [15].

\subsection{Research Objectives}

The purpose of this study is to determine which domain of interpersonal and social empathy significantly influences openness to the diversity of senior high school students of Sto. Tomas National High School. Specifically, this study will:

$R 1$. Describe the level of interpersonal and social empathy in terms of:

1.1 Macro-perspective Taking;

1.2 Cognitive Empathy;

1.3 Self-other Awareness;

1.4 Affective Response;

1.5 Contextual Understanding; and

1.6 Emotion Regulation. 
$R 2$. Describe the level of openness to diversity of senior high students in terms of:

2.1 Valuing Diversity;

2.2 Openness to Experience; and

2.3 Comfort with differences.

R3. Determine the significant relationship between interpersonal and social empathy and openness to diversity of Humanities and Social Sciences students.

R4. Determine which domain of interpersonal and social empathy significantly influences the openness to diversity of Humanities and Social Sciences students.

\subsection{Hypotheses}

Hol: There is no significant relationship between interpersonal and social empathy and openness to diversity of Humanities and Social Sciences students.

Ho2: There is no domain of interpersonal and social empathy that significantly influences the openness to diversity of Humanities and Social Sciences students.

\section{METHODOLOGY}

\subsection{Research Design}

The study utilized the descriptive-correlational method of research to determine the relationship between openness to diversity of the Humanities and Social Sciences (HUMSS) students. Descriptive-correlational design involves the calculation of two or more relevant variables and the assessment of the relationship between or between these variables [16]. In a correlation study, the researchers investigate what degree a statistical relationship exists between variables without trying to create a causal relationship [17].

\subsection{Research Locale}

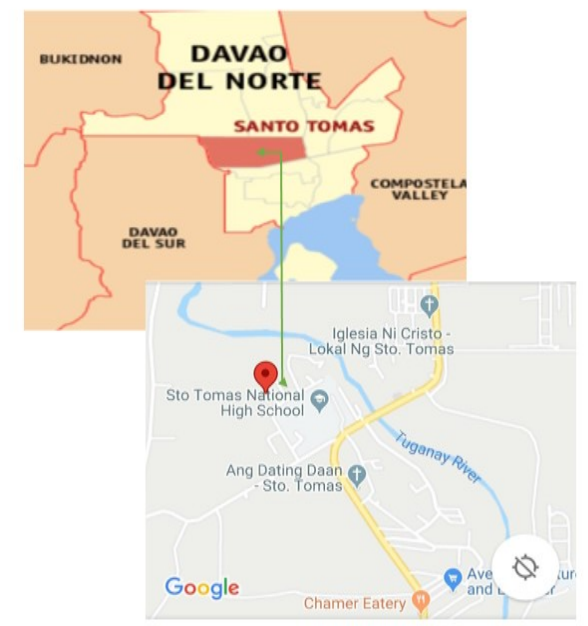

Figure 2: Geographical Map of Davao del Norte Pointing Sto. Tomas National High School
The study was conducted at Sto. Tomas National High School, Senior High School Department. Sto. Tomas National High School, is a DepEd managed public secondary school located in the $2^{\text {nd }}$ district of Davao del Norte, and known as the largest high school in the Division of Davao del Norte. For the geographical location of the municipality, it is located $125^{\circ} 30^{\prime}$ east longitude and $7^{\circ} 30^{\prime \prime}$ north latitude. Figure 2 shows the map of Davao del Norte, wherein Sto. Tomas National High School is located.

\subsection{Research Respondents}

The respondents of the study were the grade 12 students under the Humanities and Social Sciences (HUMSS) strand within Sto. Tomas National High School. The study used the method of complete enumeration in setting the samples the respondents. Complete enumeration is a full list of population, and all information from all aspects of the community is obtained. These are generally updated to the main population figures collect detailed data about each unit [18].

\subsection{Research Instruments}

The researchers adopted scales from the study Scale Development and Validation of Openness to Diversity[15] and the research paper of A Confirmatory factor analysis of Interpersonal and Social Empathy Index[11]. Interpersonal and social empathy scale and openness to diversity scale was designed to identify factors of the interpersonal and social empathy that may influence the openness to diversity of senior high school students. The instrument consists of three (3) parts, and the first part is the personal information of the respondents.

The second part is the interpersonal and social empathy scale with eighteen (18) items and six (6) subscales, which are the macro-perspective taking, cognitive empathy, self-other awareness, affective response, contextual understanding, and emotion regulation. The last part consists of the openness to diversity scale with twelve (12) items and three (3) subscales, which are the valuing to diversity, openness to experience, and comfort with differences.

The questionnaire was modified to include only the items relevant to the study. The draft was first shown to the researcher's adviser for comments and suggestions, after which experts were requested to validate the said questionnaire. After validation of the experts, the reliability of the questionnaire was tested through pilot testing Cronbach's Alpha. Cronbach's alpha reliability coefficient ranges typically between 0 and 1 . However, there is no lower limit to the coefficient. 
Table I. Interpersonal and Social Empathy Scale

\begin{tabular}{|c|c|c|}
\hline $\begin{array}{l}\text { Score } \\
\text { Intervals }\end{array}$ & $\begin{array}{l}\text { Descriptive } \\
\text { Equivalent }\end{array}$ & Interpretation \\
\hline $5.17-6.00$ & Very High & $\begin{array}{l}\text { This means that interpersonal and social } \\
\text { empathy among students is always } \\
\text { manifested. }\end{array}$ \\
\hline $4.34-5.16$ & High & $\begin{array}{l}\text { This means that interpersonal and social } \\
\text { empathy among students is oftentimes } \\
\text { manifested. }\end{array}$ \\
\hline $3.52-4.33$ & Minimum & $\begin{array}{l}\text { This means that interpersonal and social } \\
\text { empathy among students is manifested. }\end{array}$ \\
\hline $2.68-3.51$ & Low & $\begin{array}{l}\text { This means interpersonal, and social } \\
\text { empathy among students is sometimes } \\
\text { manifested. }\end{array}$ \\
\hline $1.84-2.67$ & Very Low & $\begin{array}{l}\text { This means that interpersonal and social } \\
\text { empathy among students is seldom } \\
\text { manifested }\end{array}$ \\
\hline $1.00-183$ & Extremely Low & $\begin{array}{l}\text { This means that and interpersonal and } \\
\text { social empathy among students is not } \\
\text { manifested. }\end{array}$ \\
\hline
\end{tabular}

The interpersonal and social empathy scale generated a Cronbach's alpha of .883 higher than the required .70 for the reliability of pilot-testing of the scale given to 30 respondents. The six (6) Likert type scale was used to determine and interpret the data gathered. The closer Cronbach's alpha coefficient is to 1.0 , the greater the internal consistency of the items in scale [20].

Table II. Openness to Diversity Scale

\begin{tabular}{|c|c|c|}
\hline $\begin{array}{l}\text { Score } \\
\text { Intervals }\end{array}$ & $\begin{array}{l}\text { Descriptive } \\
\text { Equivalent }\end{array}$ & Interpretation \\
\hline $5.17-6.00$ & Very High & $\begin{array}{l}\text { This means that openness to diversity and } \\
\text { among students is always manifested. }\end{array}$ \\
\hline $4.34-5.16$ & High & $\begin{array}{l}\text { This means that openness to diversity among } \\
\text { students is oftentimes manifested. }\end{array}$ \\
\hline $3.52-4.33$ & Minimum & $\begin{array}{l}\text { This means that openness to diversity among } \\
\text { students is manifested. }\end{array}$ \\
\hline $2.68-3.51$ & Low & $\begin{array}{l}\text { This means that openness to diversity among } \\
\text { students is sometimes manifested. }\end{array}$ \\
\hline $1.84-2.67$ & Very Low & $\begin{array}{l}\text { This means that openness to diversity and } \\
\text { among students is seldom manifested }\end{array}$ \\
\hline $1.00-183$ & Extremely Low & $\begin{array}{l}\text { This means that openness to diversity and } \\
\text { among students is not manifested. }\end{array}$ \\
\hline
\end{tabular}

While the openness to diversity scale garnered a Cronbach's alpha of .841 higher than the required .70 for the reliability of pilot-testing of the scale given to 30 respondents, the results concluded that the questionnaire is reliable and can be used in gathering the data of the study. The six (6) Likert-type scales are divided into six levels. The scale is shown above.

\subsection{Data Gathering Procedures}

The researchers personally distributed and administered the research instrument to the respondents to ensure one hundred $(100 \%)$ percent retrieval of the questionnaire. The survey was conducted in the second semester of the school year 20192020 at Sto. Tomas National High School, Senior High School Department. The permission letter was delivered and directly approved by the school principal of Sto. Tomas National High School. The data gathered by the researchers were tallied, tabulated, analyzed, and interpreted based on the purpose of the study. The same procedure was also done during the pilot testing to find the validity of the elements applicable to the respondents.

\subsection{Statistical Treatment}

The following statistical tools were used in the computation of the data and testing the hypothesis at the alpha 0.5 level of significance.

Mean: This was used to determine the level of interpersonal and social empathy and openness to diversity of HUMSS students.

Pearson $r$ : This was used to determine the interrelationship of interpersonal and social empathy and openness to diversity of HUMSS students.

Multiple Regression Analysis: This was used to determine the significant influence of interpersonal and social empathy toward openness to diversity of HUMSS students.

\section{RESULTS and DISCUSSIONS}

This chapter presents the summarized data gathered from the respondents of this study. This section discussed the level of interpersonal and social empathy, level of openness to diversity, the correlation between the two variables, and the significant influence of interpersonal and social empathy toward openness to diversity of Humanities and Social Sciences students.

\subsection{Level of Interpersonal and Social Empathy}

Shown in table 3, the summary of data gathered about the first objective of this study about the level of interpersonal and social empathy with its several indicators. The overall mean score of the level of the interpersonal and social empathy is 4.88 or high with a standard deviation of 0.53 . The respondents claimed that there is high interpersonal and social empathy of HUMSS students. The result suggests that HUMSS students are considerate and sensitive in terms of judging other's life.

The indicator contextual understanding got the highest mean score of 5.29, with a standard deviation of 0.84 describe as very high. This implies that respondents are empathic or conscious in a social context and have the quality to distinguished people's lives that promote justice and equity. This claim is evident that individual should consider any factors or aspects of people's way of living to conclude and 
understand their situation, especially when dealing with diversity [20].

Table III. Level of Interpersonal and Social Empathy of HUMSS Students

\begin{tabular}{|c|c|c|c|}
\hline Dimensions & Mean & SD & Description \\
\hline $\begin{array}{c}\text { Macro-Perspective } \\
\text { thinking }\end{array}$ & 4.89 & 0.69 & High \\
\hline Cognitive Empathy & 4.69 & 0.89 & High \\
\hline Self-other awareness & 4.54 & 0.83 & High \\
\hline Affective Response & 5.18 & 0.72 & Very High \\
\hline $\begin{array}{c}\text { Contextual } \\
\text { Understanding }\end{array}$ & 5.29 & 0.84 & Very High \\
\hline Emotion Regulation & 4.67 & 0.90 & High \\
\hline Overall mean & 4.88 & 0.53 & High \\
\hline
\end{tabular}

The other indicator affective response also resulted in a very high level. This means that the respondents show affection, or they would be affected by other's feelings or what people would feel. This condition was explained that there are people who could feel what others would feel [11].

\subsection{Level of Openness to Diversity}

Presented in table 4 the indicators that measured the level of openness to diversity. This includes; valuing diversity, openness to experiences, and comfort with differences. The results revealed an overall mean score of 4.91, with a standard deviation of 0.70 , descriptively interpreted as high.

Openness to a diversity of senior high school students got a high overall mean rating of 4.91, which implies that the respondents are open in different cultures and beliefs that promotes socialization, and they accepted diversity. Therefore, senior high school students, specifically HUMSS students, discourage ethnocentrism or cultural bias. They are open-minded and appreciative of social differences that decrease disaccord. The result is connected to the claim, that openness to diversity will promote peer engagements and diminish conflict in society [14].

The indicator that got a high mean score of 5.36 and a standard deviation of 0.84 with a descriptive level of very high is the openness to experience. This signifies that the respondents are ready and wide open to embrace new experiences to undertake. They are smart and believe in creating more intelligent ideas because of new knowledge perceived by their experiences. This claim was supported, that openness to experience will help to produce productive ideas and, at the same time, opens vast opportunities [21].

Table IV. Level of Openness to Diversity of HUMSS Students

\begin{tabular}{|c|c|c|c|}
\hline Dimensions & Mean & SD & Description \\
\hline Valuing Diversity & 4.70 & 0.79 & High \\
\hline $\begin{array}{c}\text { Openness to } \\
\text { Experience }\end{array}$ & 5.36 & 0.84 & Very High \\
\hline $\begin{array}{c}\text { Comfort with } \\
\text { differences }\end{array}$ & 4.66 & 0.86 & High \\
\hline Overall mean & 4.91 & 0.70 & High \\
\hline
\end{tabular}

\subsection{Significance of the Relationship between Interpersonal and Social Empathy and the Openness to Diversity}

Table 5 presents the summary of the computations of results of the relationship between interpersonal and social empathy and openness to diversity with an overall r-value of 0.592 and a p-value of 0.000 , which is less than 0.05 . This finding means that there is a positive, moderately high significant correlation between interpersonal and social empathy and openness to diversity of Humanities and Social Sciences students. Thus, the null hypothesis is, therefore, rejected. This indicates that the interpersonal and social empathy of the students is significant and relevant to being open with diversity.

Moreover, this implies that the interpersonal and social empathy of the respondents help them become more open in diversity. The result means that HUMSS students are observed to be unbiased, and they are culturally intelligent, and they have high potential in dealing with diversity without any judgments. This corroborate with the assertion that interpersonal empathy optimized anti-social actions, especially when facing society [11]. Furthermore, it was concurred with the results of this study, stating that empathy plays an essential role in communicating with one another despite the diversity that precedes knowledge and personal relationship toward another [22].

Table V. Significance on the Relationship between Interpersonal and Social Empathy and Openness to Diversity

\begin{tabular}{|c|c|c|c|c|}
\hline \multirow{2}{*}{$\begin{array}{c}\text { Interpersona } \\
\text { and Social } \\
\text { Empathy }\end{array}$} & \multicolumn{4}{|c|}{ Openness to Diversity } \\
\cline { 2 - 5 } & $\begin{array}{c}\text { Valuing } \\
\text { Diversity }\end{array}$ & $\begin{array}{c}\text { Openness } \\
\text { to } \\
\text { Experience }\end{array}$ & $\begin{array}{c}\text { Comfort } \\
\text { with } \\
\text { Differences }\end{array}$ & Overall \\
\hline $\begin{array}{c}\text { Macro- } \\
\text { Perspective } \\
\text { taking }\end{array}$ & $.415^{* *}$ & $.535^{* *}$ & $.359^{* *}$ & $.521^{* *}$ \\
\cline { 2 - 5 } & $(.000)$ & $(.000)$ & $(.000)$ & $(.000)$ \\
\hline $\begin{array}{c}\text { Cognitive } \\
\text { Empathy }\end{array}$ & $.415^{* *}$ & $.520^{* *}$ & $.329^{* *}$ & $.517^{* *}$ \\
\cline { 2 - 5 } & $(.000)$ & $(.000)$ & $(.000)$ & $(.000)$ \\
\hline \multirow{2}{*}{$\begin{array}{c}\text { Self- other } \\
\text { Awareness }\end{array}$} & $.443^{* *}$ & $.407^{* *}$ & $.342^{* *}$ & $.474^{* *}$ \\
\cline { 2 - 5 } & $(.000)$ & $(.000)$ & $(.000)$ & $(.000)$ \\
\hline \multirow{2}{*}{$\begin{array}{c}\text { Affective } \\
\text { Response }\end{array}$} & $.319^{* *}$ & $.516^{* *}$ & $.297^{* *}$ & $.452^{* *}$ \\
\cline { 2 - 5 } & $(.000)$ & $(.000)$ & $(.001)$ & $(.000)$ \\
\hline $\begin{array}{c}\text { Contextual } \\
\text { Understandi } \\
\text { ng }\end{array}$ & $.299^{* *}$ & $.392^{* *}$ & $.335^{* *}$ & $.410^{* *}$ \\
\cline { 2 - 5 } & $(.001)$ & $(.000)$ & $(.000)$ & $(.000)$ \\
\hline \multirow{2}{*}{$\begin{array}{c}\text { Emotion } \\
\text { Regulation }\end{array}$} & .055 & .066 & .018 & .055 \\
\cline { 2 - 5 } & $(.548)$ & $(.469)$ & $(.841)$ & $(.544)$ \\
\hline \multirow{2}{*}{\begin{tabular}{c} 
Overall \\
\cline { 2 - 5 }
\end{tabular}} & $.485^{* *}$ & $.591^{* *}$ & $.411^{* *}$ & $.592^{* *}$ \\
\cline { 2 - 5 } & $(.000)$ & $(.000)$ & $(.000)$ & $(.000)$ \\
\hline
\end{tabular}

\subsection{Significance of the Influence of Interpersonal and Social Empathy toward Openness to Diversity}

Presented in table 6 are the regression coefficients to test which domain of interpersonal and social empathy significantly influence the openness to diversity of Humanities and Social Sciences students. The data revealed the $F$-value 
13.413 and the p-value of .000 or significant. This means that the interpersonal and social empathy of Humanities and Social Sciences students influence their openness to diversity.

The $r^{2}$ of 0.410 implies that $41 \%$ of the variance of the openness to diversity is explained by interpersonal and social empathy while the other $59 \%$ is contributed by other factors not included in this study. On the other hand, it was revealed in the study that macro-perspective taking and self-other awareness are the domains of the interpersonal and social empathy that significantly influence the openness to diversity. The remaining four indicators scored higher than set a significant level, and do not significantly influence openness to diversity. Therefore, the null hypothesis of this study is therefore rejected.

Table VI. Significance on the influence of Interpersonal and Social Empathy toward Openness to Diversity

\begin{tabular}{|c|c|c|c|c|}
\hline \multirow{2}{*}{$\begin{array}{c}\text { Interpersonal and } \\
\text { Social Empathy }\end{array}$} & $B$ & $\beta$ & $t$ & Sig. \\
\cline { 2 - 5 } & .311 & .308 & 2.874 & .005 \\
\hline $\begin{array}{c}\text { Macro-Perspective } \\
\text { taking }\end{array}$ & .073 & .085 & .750 & .455 \\
\hline $\begin{array}{c}\text { Cognitive Empathy } \\
\text { Self- other Awareness }\end{array}$ & .216 & .258 & 2.888 & .005 \\
\hline Affective Response & .067 & .069 & .715 & .476 \\
\hline $\begin{array}{c}\text { Contextual } \\
\text { Understanding }\end{array}$ & .109 & .131 & 1.510 & .134 \\
\hline Emotion Regulation & -.030 & -.039 & -.531 & .596 \\
\hline \multicolumn{5}{|c|}{$\mathrm{R}=.640$} \\
\hline \multicolumn{5}{|c|}{$\mathrm{F}=13.413$} \\
\hline $\mathrm{P}=.000$ \\
\hline \multicolumn{5}{|c|}{.410} \\
\hline
\end{tabular}

The results affirm that macro-perspective taking is a necessary process that is to experience other's life experience to understand them or to comprehend other's way of life by being conscious of what it might look like if they are living from different culture that they used to, that will lead them to enhance being open with diversity [11]. Moreover, it was revealed that self-other awareness is a critical ability to differentiate own experiences and knowledge from others [11]. Additionally, it was stated that it is one's way of being conscious and aware of other's inner state. It is an essential trait, especially when dealing with diversity because when everyone has the awareness that we are different from each other, then we can deplete judgments [23].

\section{CONCLUSIONS AND RECOMMENDATIONS}

\subsection{Summary}

This study assessed the level of interpersonal and social empathy and openness to diversity of Humanities and Social Sciences students. The study also delves if there is a significant relationship between the two variables, and what factor of interpersonal and social empathy best influences the openness to diversity of HUMSS students. Primary data were collected directly from the respondents through two adapted scales. The descriptive-correlation method of research was used to attain the study's objectives. The respondents of this study were the 123 grade 12 HUMSS students currently studying at Sto. Tomas National High School.

The findings of the study revealed that the level of interpersonal and social empathy and openness to diversity of senior high school students are both high. It was also revealed that there is a positive high significant relationship between interpersonal and social empathy and openness to diversity. Moreover, it was found out that the macro-perspective taking and self-other awareness are the domains that significantly influence openness to diversity. This means that if the students show consideration and sensible with other's way of living there is a big possibility that they are open with diversity.

\subsection{Conclusions}

Based on the findings, the following conclusions were formulated:

1. The data revealed a high level of interpersonal and social empathy. Therefore, HUMSS students are very considerate, and they are empathic people.

2. The results showed a high level of openness to diversity. Therefore, the respondents are open-minded in diversity. They did not think that their own culture, beliefs, and norms are better than others. Furthermore, they disregard the idea of ethnocentricity, which shows a biased attitude to one's group that does not belong to them.

3. There is a positive, moderately high significant relationship between interpersonal and social empathy and openness to diversity. Therefore, the interpersonal and social empathy of the HUMSS students helps them become more open in diversity. This suggests that if the students are showing empathy and consideration with others are more open in diversity. Furthermore, interpersonal and social empathy help students to be more likely open-minded in diversity.

4. Macro-perspective taking and self-other awareness significantly influence the openness to diversity of HUMSS students. This implies that if students are considerate and conscious with others' state, therefore, they are more likely to be open-minded and shows respect with other's beliefs, culture, and norms that are different from their group. This attitude improves social communication and relationship that is very important, especially when dealing with diversity.

\subsection{Recommendations}

In light of the foregoing findings, the following recommendations are offered.

1. Department of Education could initiate more activities such as team building and other student engaging 
activities which encourage openness to diversity. They may also provide programs that will help inculcate macro-perspective thinking and self-other awareness of students for them to constantly be open for the diverse way of life of their colleagues.

2. Teachers should consider macro-perspective taking and self-other awareness in enlightening the minds of their students when dealing with diverse culture. Since, if the students are aware and open about the diverse way of life of others then they can help lessen prejudice, social inequality, and biased treatment to others.

3. Students, especially HUMSS students, must comprehensively understand macro-perspective taking and self-other awareness to be able for them to be open in diversity by putting their selves in someone's situation and by knowing and understanding differences of other people since they are expected to be the future public servants of their own community.

4. Future researchers could find more than half of the variance that is under the other factors not covered in this study that would significantly influence openness to diversity. They may also conduct further investigations about openness to diversity with other setting.

\section{ACKNOWLEDGEMENT}

We would like to express sincere gratitude and heartfelt appreciation to the following individuals and entities whose generous support and cooperation made the writing of this study possible: To our classmates, for the constant support and for sharing their thoughts and ideas in helping us to complete our research paper; To our dear parents, who supported us financially and by giving us the moral support and inspiration upon making this research paper;And above all the Almighty God, for His unconditional love and for giving us the knowledge and wisdom in making all these possible.

\section{REFERENCES}

[1] Lauring, J., \& Selmer, J. (2012). Openness to diversity, trust and conflict in multicultural organizations. Journal of Management \& Organization, 18(6), 795-806. Retrieve from: https://www.researchgate.net/publication/269638088_Openness_to _diversity_trust_and_conflict_in_multicultural_organizations

[2] Bizumic, B., Segal, E. I. R., \& von Stuckrad, K. Boris Bizumic Research School of Psychology The Australian National University. Retrieve from: https://www.academia.edu/37525723/Ethnocentrism

[3] Stegmann, S., Roberge, M., \& Rolf, v. D. (2012). Getting tuned in to those who are different: The role of empathy as mediator between diversity and performance. ZeitschriftFürBetriebswirtschaft, 82(2), 19-44. Retrieve from: doi:http://dx.doi.org/10.1007/s11573-011-0543-y

[4] Ruggs, E., \&Hebl, M. (2012). Literature overview: Diversity, inclusion, and cultural awareness for classroom and outreach education. Apply research to practice(ARP)resources.Retrievedfromhttps://www.engr.psu.edu/a we/ARPAbstracts/Diversity Inclusion $\quad / A P_{-}$ DiversityInclusionCulturalAwareness_Overview. pdf.
[5] Ozman, M., \&Erdil, E. (2013). Cultural Diversity, Knowledge Diversity. Retrieve from: http://www.ub.edu/searchproject/wpcontent/uploads/2013/09/WP5.16.pdf

[6] Mazur, B. (2010). Cultural diversity in organisational theory and practice. Journal of intercultural management, 2(2), 5-15. Retrieve from: http://31.186.81.235:8080/api/files/view/7178.pdf

[7] Gawali, G., \&Khattar, T. (2016). The influence of multicultural personality on attitude towards religious diversity among youth. Journal of the Indian Academy of Applied Psychology, 42(1), 114-123. Retrieve from: https://psycnet.apa.org/record/2016-10256-011

[8] Turner, J. C., \&Tajfel, H. (1986). The social identity theory of intergroup behavior. Psychology of intergroup relations, 5, 7-24. Retrieve

from: http://christosaioannou.com/Tajfel\%20and\%20Turner\%201986.pd $\mathrm{f}$

[9] Hoffman, M., 1990. Empathy and Justice Motivation. Motivation and Emotion, 14(2),pp.151-172. Retrieve from: https://link.springer.com/article/10.1007/BF00991641

[10] Vygotsky, L. S. (1980). Mind in society: The development of higher psychological processes. Harvard university press.

[11] Segal, E. A., Cimino, A. N., Gerdes, K. E., Harmon, J. K., \&Wagaman, M. A. (2013). A confirmatory factor analysis of the interpersonal and social empathy index. Journal of the Society for Social Work and Research,4(3), 131-153. Retrieve from: https://psycnet.apa.org/record/2013-33288-001

[12] Walter, H. (2012). Social cognitive neuroscience of empathy: Concepts, circuits, and genes. Emotion Review, 4(1), 9-17. Retrieve from: doi: $10.1177 / 1754073911421379$

[13] Hollan, D. (2012). Emerging issues in the cross-cultural study of empathy. Emotion Review, 4(1), 70-78. Retrieve from: doi: $10.1177 / / 1754073911411376$

[14] Longerbeam, S. D. (2010). Developing openness to diversity in living-learning program participants. Journal of Diversity in Higher Education, 3(4), 201. Retrieve from: https://www.researchgate.net/publication/232522177_Developing Openness_to_Diversity_in_Living-

Learning_Program_Participants

[15] Singh, M. R., \& Shah, R. SCALE DEVELOPMENT AND VALIDATION OF OPENNESS TO DIVERSITY. Retrieve from: https://www.semanticscholar.org/paper/SCALE-

DEVELOPMENT-AND-VALIDATION-OF-OPENNESS-TOMs-SinghShah/f57b9f575cea6a673dbbbf402b8c73d8538d8988

[16] Stangor, C. \&Walinga, J. (2019). 3.5 Psychologists Use Descriptive-Correlational, and Experimental Research Designs to Understand Behaviour. Introduction to Psychology. Retrieve from: https://pressbooks.nscc.ca/introductiontopsychology/chapter/2-2psychologists-use-descriptive-correlational-and-experimentalresearch-designs-to-understand-behavior/

[17] Quaranta, J. (2017). Descriptive Correlational Research: Asthma Management by School Nurses. SAGE Publications Ltd. Retrieved from:https://methods.sagepub.com/case/descriptivecorrelationalresearch-asthma-management-school-nurses

[18] Molenberghs, G. (2010). Survey methods \& Sampling techniques. Interuniversity Institute for Biostatistics and statistical Bioinformatics (I-BioStat), 31(2), 12-34. Retrieve from: https://soc.kuleuven.be/ceso/historischedemografie/resources/pdf/ ML/survey10.pdf

[19] Tavakol, M., \&Dennick, R. (2011). Making sense of Cronbach's alpha. International journal of medical education,2,53.Retrieved from: https://www.ijme.net/archive/2/cronbachs-alpha.pdf

[20] Dash, N. S. (2008). Context and contextual word meaning. SKASE Journal of Theoretical Linguistics.

[21] Kaufman, S. B., Quilty, L. C., Grazioplene, R. G., Hirsh, J. B., Gray, J. R., Peterson, J. B., \&DeYoung, C. G. (2016). Openness to experience and intellect differentially predict creative achievement in the arts and sciences. Journal of personality, 84(2), 248-258. Retrieve from: https://scottbarrykaufman.com/wpcontent/uploads/2015/01/Kaufman-et-al.-2015.pdf

[22] Valente, F. (2016). Empathy and Communication: A Model of Empathy Development. Journal of New Media and Mass 
International Journal of Research and Innovation in Social Science (IJRISS) |Volume V, Issue IV, April 2021|ISSN 2454-6186

Communication, 3(1), 1-24. Retrieve from: https://ideas.repec.org/a/pkp/jnmams/2016p1-24.html

[23] Sutton, A. (2016). Measuring the effects of self-awareness:

Construction of the self-awareness outcomes questionnaire. Europe's journal of psychology, 12(4), 645. Retrieve from: https:/www.semanticscholar.org/paper/Measuringthe-Effects-of-Self-Awareness $\% 3 \mathrm{~A}$-of-the-

Sutton/987f0c70b542ea2032874bff92845e20665eb214 